\title{
"I Believe It Is Wrong But I Still Do It": A Comparison of Religious Young Men Who Do Versus Do Not Use Pornography
}

\author{
Larry J. Nelson \\ Brigham Young University - Provo \\ Laura M. Padilla-Walker \\ Brigham Young University - Provo \\ Jason S. Carroll \\ Brigham Young University - Provo, jcarroll@byu.edu
}

Follow this and additional works at: https://scholarsarchive.byu.edu/facpub

Part of the Other Social and Behavioral Sciences Commons

\section{Original Publication Citation}

Nelson, L. J., Padilla-Walker, L. M., \& Carroll, J. S.(2010). “I Believe It Is Wrong But I Still Do It”: A Comparison of Religious Young Men Who Do Versus Do Not Use Pornography. Psychology of Religion and Spirituality, 2, 136-147.

\section{BYU ScholarsArchive Citation}

Nelson, Larry J.; Padilla-Walker, Laura M.; and Carroll, Jason S., "'I Believe It Is Wrong But I Still Do It": A Comparison of Religious Young Men Who Do Versus Do Not Use Pornography" (2010). Faculty Publications. 4348.

https://scholarsarchive.byu.edu/facpub/4348 


\title{
"I Believe It Is Wrong But I Still Do It": A Comparison of Religious Young Men Who Do Versus Do Not Use Pornography
}

\author{
Larry J. Nelson, Laura M. Padilla-Walker, and Jason S. Carroll \\ Brigham Young University
}

\begin{abstract}
While researchers have found a negative association between religiosity and pornography use, little, if any, research has examined the specific aspects of religiosity that might be related to the use of pornography. Therefore, the purpose of this study of religious young men was to compare those who view pornography with those who do not on indices of (a) family relationships, (b) religiosity (i.e., beliefs, past/present personal religious practices, and past family religious practices), and (c) personal characteristics (identity development, depression, self-esteem, and drug use). Participants were 192 emerging-adult men ages $18-27(M$ age $=21.00, S D=3.00)$ attending a religious university in the Western United States. While they all believed pornography to be unacceptable, those who did not use pornography (compared to those who did) reported (a) higher levels of past and recent individual religious practices, (b) past family religious practices, (c) higher levels of self-worth and identity development regarding dating and family, and (d) lower levels of depression.
\end{abstract}

Keywords: pornography, emerging adulthood, religiosity, identity

Emerging adulthood (individuals approximately $18-27$ years of age) is characterized by self-exploration and experimentation of sexual values and behaviors (Arnett, 2000). Research suggests that pornography use may be one way in which young people are experimenting during this time period in that its use has become prevalent among college students, particularly men (e.g., Boies, 2002). Indeed, Carroll and colleagues (2008) found that nearly 9 out of 10 college men reported viewing pornography in the last year. Specifically, they found that $87 \%$ of emerging-adult men used pornography to some degree, with one in five viewing it daily or every other day, compared to only $31 \%$ of women who reported some degree of use and $3 \%$ of women using daily or every other day. Results of this study also showed that $67 \%$ of the young men believed to some degree that viewing pornography was an acceptable way to

Larry J. Nelson, Laura M. Padilla-Walker, and Jason S. Carroll, School of Family Life, Brigham Young University.

We thank the instructors and students who assisted in data collection. We also are grateful for the grant support of the Family Studies Center and Religious Studies Center at Brigham Young University.

Correspondence concerning this article should be addressed to Larry J. Nelson, 2091 JFSB, School of Family Life, Brigham Young University, Provo, UT 84602. E-mail: larry_nelson@byu.edu express one's sexuality, compared to $49 \%$ of young women, $37 \%$ of fathers, and $20 \%$ of mothers in the sample.

The acceptability of pornography can also be seen in the work of Goodson, McCormick, and Evans (2000), in which college students were asked how they felt when viewing sexually explicit material on the Internet. Results showed that only $18 \%$ felt embarrassed, $20 \%$ felt uncomfortable, $24 \%$ felt guilty, and only $29 \%$ were concerned about being caught or judged if found out. Taken together, these findings suggest general acceptance of pornography. Indeed, the degree to which pornography use is considered normative among today's young men is quite staggering given the extent to which their female peers and their parents disagree with its use.

However, Carroll and colleagues'(2008) findings that $67 \%$ of the men believed pornography to be acceptable but $87 \%$ of them reported using it suggests that there was a portion of young men who reported viewing pornography despite believing it to be an unacceptable behavior. The notion of cognitive dissonance (e.g., Stone, 2008) would suggest that problems may occur for individuals when a discrepancy between their beliefs and behaviors exists. Little is known about this possible dissonance and its correlates in regard to pornography acceptance and use. 
While there may be several reasons why one develops a personal ethic against the use of pornography, there is reason to believe that religiosity may be one such factor. Much of this evidence, however, stems from work done with adolescents rather than emerging adults. For example, Regnerus (2007) examines the sexual values and practices of adolescents in America with a particular focus on the role of religion in shaping beliefs, attitudes, and behaviors related to sexuality, including pornography. This work suggests that albeit complex, there are associations between religiosity and both attitudes and (to a lesser extent) behaviors related to sexuality. Albeit it sparse, the work in emerging adulthood also suggests that religion may be a reason why a person may develop personal beliefs and attitudes suggesting that pornography use is wrong. Goodson and colleagues (2000) found that neither religious preference (i.e., affiliation) nor religiosity was related to using the Internet to search for sexually explicit material, but religiosity was a small but significant negative predictor of feeling entertained and aroused by pornography. In other words, religious individuals may view pornography, but may feel negatively when doing it due to religious rules or tenets against such behavior. Carroll et al. (2008) found a significant negative correlation between religiosity and pornography acceptance $(r=-.39)$ and use $(r=-.30)$ and therefore controlled for religiosity in their analyses.

Taken together, there is evidence to suggest that religiosity may play a role in beliefs about and usage of pornography. Furthermore, religiosity may potentially explain why some individuals experience cognitive dissonance caused by not accepting pornography but still using it. One of the reasons why religiosity may be an important context in which to examine the disconnect between beliefs and behaviors regarding pornography use is because of the expressed views of faith traditions regarding pornography. In many Judeo-Christian religions, viewing pornography is commonly viewed as breaking the commandment "Thou shalt not commit adultery" (Exodus 20:14) because of teachings that connect lusting after a woman as being the same as the actual act of committing adultery or fornication (e.g., Matthew 5:28). Further, many religions explicitly teach that viewing pornography is wrong and have led "crusades" against pornography in recent years (see Sherkat \&
Ellison, 1997). Finally, indicative of the teachings received by participants in the current study, a leader of the church to whom the participants of this study belong (The Church of Jesus Christ of Latter-day Saints) has taught about pornography, "[a]void it like the plague because it is just as deadly, more so. The plague will destroy the body. Pornography will destroy the body and the soul. Stay away from it! It is as a great disease that is sweeping over the country and over the entire world." (Hinckley, 2000, p. 18).

In sum, there may be an internal struggle for religious individuals who are taught that pornography is wrong, but who then still use it. The purpose of this paper was to examine a sample of religious young men who all agree that pornography is unacceptable but who differ in their usage patterns. Specifically, the purpose of this study of religious young men who believe pornography to be an unacceptable behavior, was to compare those who then view pornography with those who do not on indices of (a) family relationships, (b) religiosity (i.e., past/present personal religious practices, and past family religious practices), and (c) personal characteristics (identity development, depression, selfesteem, and drug use).

In regard to family relationships, it was hypothesized that young men who view pornography would have lower quality relationships with their parents. The correlational nature of the data used in this study will preclude an examination of the causal pathways in the relations between variables, but regardless there is reason to believe that pornography use would be associated with the parent-child relationship. First, it may be that since the parents have been primary socialization agents in religious development (for a review, see Barry, Nelson, Davarya, \& Urry, in press), children feel that their pornography use is a violation of those teachings and they, therefore, withdraw from their parents as measured by lower quality relationships with them. Second, it may be that lower quality relationships with parents lead young men-whether via defiance, seeking compensation, and so forth - to engage in behaviors (i.e., pornography use) that conflict with their parents' teachings. Regardless of the direction of effects, there is reason to suspect that pornography use by religious individuals would be linked to lower quality relationships with parents. 
In regard to religious practices, it was expected that young men who view pornography would engage in fewer religious practices than their peers who do not view pornography. In the absence of longitudinal data, attempts were made in this study to examine both concurrent religious practices and retrospective reports of religious practices engaged in while growing up in order to begin to tap (as well as possible given the cross-sectional nature of the data) the role of early family and personal religious practices on pornography use. Specifically, participants were asked to retrospectively consider the extent to which they engaged in religious practices (e.g., prayer, scripture reading) individually and as a family while growing up, as well as the extent to which they engage in those practices currently as an individual. Few studies have examined early socialization of religious practices on behavior in emerging adulthood, let alone specifically about pornography use. However, Gunnoe and Moore (2002) found that religiosity of young adults ages 17 to 22 was best predicted by the presence of religious models during childhood and adolescence. Based on this minimal evidence, there was reason to expect early participation in religious activities (both as a family and individually) to be negatively related with pornography use in emerging adulthood.

Regarding current religious practices, it may be that young people who view pornography feel embarrassed or guilty (e.g., Goodson et al., 2000) about their behavior and, therefore, do not participate in religious activities such as attending church or saying prayers. On the other hand, by not engaging in practices that would remind the individual of the teachings against pornography and, thereby, reinforcing personal beliefs about pornography, young people who engage in fewer religious practices may be more likely to view pornography. Regardless of the direction of effect, it was hypothesized that young men who view pornography would have lower levels of current religious practices.

Finally, in regard to personal characteristics (identity, depression, self-esteem, and drug use) it was expected that those who viewed pornography would be less certain about their identity, more depressed, have lower self-esteem, and have higher rates of drug use. Again, there is very little extant literature upon which we might make hypotheses with the exception that Carroll and colleagues (2008) found that pornography use was found to be moderately correlated with emerging-adult men's frequency of alcohol consumption and their rates of binge drinking, and acceptance of pornography was found to be correlated with their sexual attitudes (higher pornography use was linked to more permissive attitudes regarding sexuality) and family formation values (e.g., higher pornography use was linked to greater acceptance of cohabitation). Thus, there is reason to expect a correlation between pornography use and personal characteristics in the current study.

In sum, the purpose of this study of religious emerging-adult men was to compare those who view pornography with those who do not on indices of (a) family relationships, (b) religiosity (i.e., past/present personal religious practices, and past family religious practices), and (c) personal characteristics (identity development, depression, self-esteem, and drug use). It was expected that those religious men who viewed pornography would, compared to their peers who did not view pornography, have (a) lower quality relationships with parents, (b) lower ratings of family and personal religious practices while growing up, (c), lower ratings of current personal religious practices, (d) lower ratings of identity, (e) lower self-esteem, (f), higher levels of depression, and (g) higher levels of drug use.

\section{Method}

\section{Participants}

Participants were 190 emerging adult men aged 18-27 $(M$ age $=21.00, S D=3.00)$ attending a religious university in the Western United States. Ninety-three percent of participants were European American, and 95\% lived outside the parental home in a dormitory or apartment building. Thirty-six percent of the sample identified themselves as in their first year of college, $20 \%$ in their second year, $24 \%$ in their third year, $15 \%$ in their fourth year, and $5 \%$ in their fifth year.

\section{Procedure}

Participants completed the [Project Name] questionnaire via the Internet (see [Project Internet site removed for masked review]). The 
use of an online data collection allowed for the survey to be administered to emerging adults and their parents who were living in separate locations throughout the country (parent data were not used in the current study). Participants were recruited through faculty announcement of the study in undergraduate courses. Professors were provided with a handout to give to their students that had a brief explanation of the study and directions for accessing the online survey, and students were offered extra credit for participation. Interested students then accessed the study website with a course-specific recruitment code. Informed consent was obtained online, and only after consent was given could the participants begin the questionnaires. Each participant was asked to complete a survey battery of 448 items. Sections of the survey addressed topic areas such as background information, family of-origin experiences, self-perceptions, personality traits, values, risk behaviors, dating behaviors, prosocial behaviors, and religiosity. The survey also assessed attitudes and behaviors pertaining to couple formation such as cohabitation, sexuality, and interpersonal competencies.

\section{Measures}

The current study assessed pornography use, family relationships (parent-child relationship quality, closeness to $\mathrm{dad}$, and closeness to mom), religious beliefs and practices (religious faith, past religious practices, current religious practices, family religious practices), and personal characteristics (identity, self-esteem, depression, and drug use) of the emerging adult.

Pornography acceptance and use. Two items were used to measure participants' levels of acceptance and use of pornography. Acceptance of pornography was measured by asking respondents how much they agreed with the statement: "Viewing pornographic material (such as magazines, movies, and/or Internet sites) is an acceptable way to express one's sexuality." Responses were recorded on a sixpoint scale ranging from 1 (very strongly disagree) to 6 (very strongly agree). Based on previous work (Carroll et al., 2008), pornography use was assessed by asking emerging adults the question: "During the past 12 months, on how many days did you view pornographic materials (such as magazines, movies, and/or
Internet sites)?" Responses for this item were measured on a six-point scale $(0=$ none, $1=$ once a month or less, $2=2$ or 3 days a month, $3=1$ or 2 days a week, $4=3$ to 5 days a week, 5 = everyday or almost every day). All men who viewed pornography at least once a month over the past year were collapsed into a group labeled "pornography users" while those who responded "none" were categorized as "pornography non users."

Family relationships. Parent-child relationship quality was assessed using the shortversion of the Social Provisions Questionnaire (Carbery \& Buhrmester, 1998). Participants rated 18 items regarding their relationship with their parent $(66 \%$ responded about mother, $34 \%$ about father). Sample items include, "How happy are you with the way things are between you and this person?" and "How often do you turn to this person for support with personal problems?" Ratings were made on a 5-point Likert-type scale that ranged from 1 (little or none) to 5 (the most). Higher scores were indicative of higher parent-child relationship quality $(\alpha=.91)$.

Closeness to mother and father were measured using the Parent-Child Closeness Scale (Buchanan, Maccoby, \& Dornbusch, 1991). Emerging adults responded to nine items assessing paternal and maternal closeness (18 items total). Sample items include, "How openly do you talk with your (father/mother)?" and "How well does your (father/mother) know what you are really like?" Items were rated on a 5-point scale ranging from 1 (not at all) to 5 (very). Individual items were averaged for fathers and mothers, with higher scores representing emerging adults' feelings of greater maternal $(\alpha=.88)$ and paternal closeness $(\alpha=.92)$.

Religious beliefs and practices. Conviction of religious faith was assessed using the Santa Clara Strength of Religious Faith Questionnaire (Lewis, Shevlin, McGuckin, \& Navratil, 2001), which is a well-established measure that has demonstrated adequate reliability and validity with adolescent and adult populations. Participants responded to 10 items regarding their religious faith (e.g., "My religious faith is extremely important to me," "I look to my faith as providing meaning and purpose in my life") on a Likert-type scale ranging from 1 (strongly disagree) to 4 (strongly agree). Items were av- 
eraged with higher scores representing higher self-reported religious faith $(\alpha=.98)$.

Participants were asked six questions about the extent to which they engaged in religious practices in various settings (i.e., personal and family) at various times in their lives (past and present). Participants were asked to respond on a scale from 1 (never) to 7 (daily) regarding personal religious practices while growing up (e.g., "While growing up, how often did you offer personal prayers?" and "While growing up, how often did you personally study the scriptures?"; $\alpha=.78$ ), recent personal religious practices (e.g., "During the past 12 months, how often have you offered personal prayers?" and "During the past 12 months, how often have you studied the scriptures?"; $\alpha=.68$ ), and family religious practices while growing up (e.g., "While growing up, how often did you have family prayer?" and "While growing up, how often did your family study the scriptures together?"; $\alpha=.87$ ).

Personal characteristics. Identity was measured using a shortened version of the Ego Identity Process Questionnaire (Balistreri, Busch-Rossnagel, \& Geisinger, 1995), which considers 20 statements regarding individuals' commitment and exploration on various aspects of identity, including religion, values, family, and dating. Sample items include, "I have considered adopting different kinds of religious beliefs," "There has never been a need to question my values," "I have evaluated many ways in which I fit into my family structure," and "I am not quite sure about what type of dating relationship is best for me." Participants rated each statement on a 6-point scale with values ranging from 1 (strongly disagree) to 6 (strongly agree). Items were reverse scored where necessary so high scores represented higher levels of exploration and commitment. Items were summed within each of the subscales, with higher scores indicating higher levels of both exploration and commitment, which is indicative of being identity achieved. These scores were calculated for identity development in regards to religion, values, family, and dating.

Self-esteem was assessed using the SelfPerception Profile for College Students (Neeman \& Harter, 1986). Participants rated six items on a Likert-type scale from 1 (not at all true for me) to 4 (very true for me). Sample items include "I like the kind of person I am," and "I am happy being the way I am." Higher scores were indicative of higher self-esteem $(\alpha=.80)$.

Depression was assessed by reversing the happiness subscale of The Adult Temperament Scale (Rothbart, Ahadi, \& Evans, 2000). Items for depression included sad and blue, hopeless, and depressed. On a 5-point Likert-type scale ranging from 1 (never) to 5 (always), participants responded to how often they would describe themselves in this manner. Higher scores represent higher levels of self-reported depression $(\alpha=.85)$.

Drug use was assessed using four items from the Add Health Questionnaire (www.cpc.unc.edu/ addhealth/). Emerging adults were asked how many days in the past 12 months they drank alcohol, engaged in binge drinking, used marijuana and used other illegal drugs (e.g., cocaine, heroin, crystal meth, and mushrooms). Participants rated these items on a 6-point Likert-type scale ranging from 0 (none) to 5 (almost every day). Higher scores were indicative of higher drug use $(\alpha=.96)$.

\section{Results}

\section{Preliminary Analyses}

Frequencies revealed that $65 \%$ of religious young men reported viewing no pornography in the past 12 months (despite the fact that fully $100 \%$ of the sample reported that viewing pornography was an unacceptable way to express sexuality). For those that did report viewing pornography in the last year, $17.7 \%$ reported viewing once a month or less, $8.6 \%$ reported viewing two or three days per month, and $8.6 \%$ reported viewing daily or every other day.

Bivariate correlations were conducted between all study variables, and were only considered significant at $p<.01$ to avoid Type I errors (see Table 1). In particular, it should be noted that pornography acceptance and use were negatively correlated with family relationships, religious beliefs and practices, and selfworth; and were positively correlated with depression and drug use (pornography use only).

Although $100 \%$ of the sample reported that pornography was unacceptable, some might argue that the strength of religious beliefs mediates the dissonance between not accepting pornography and using it. Therefore, to insure that 


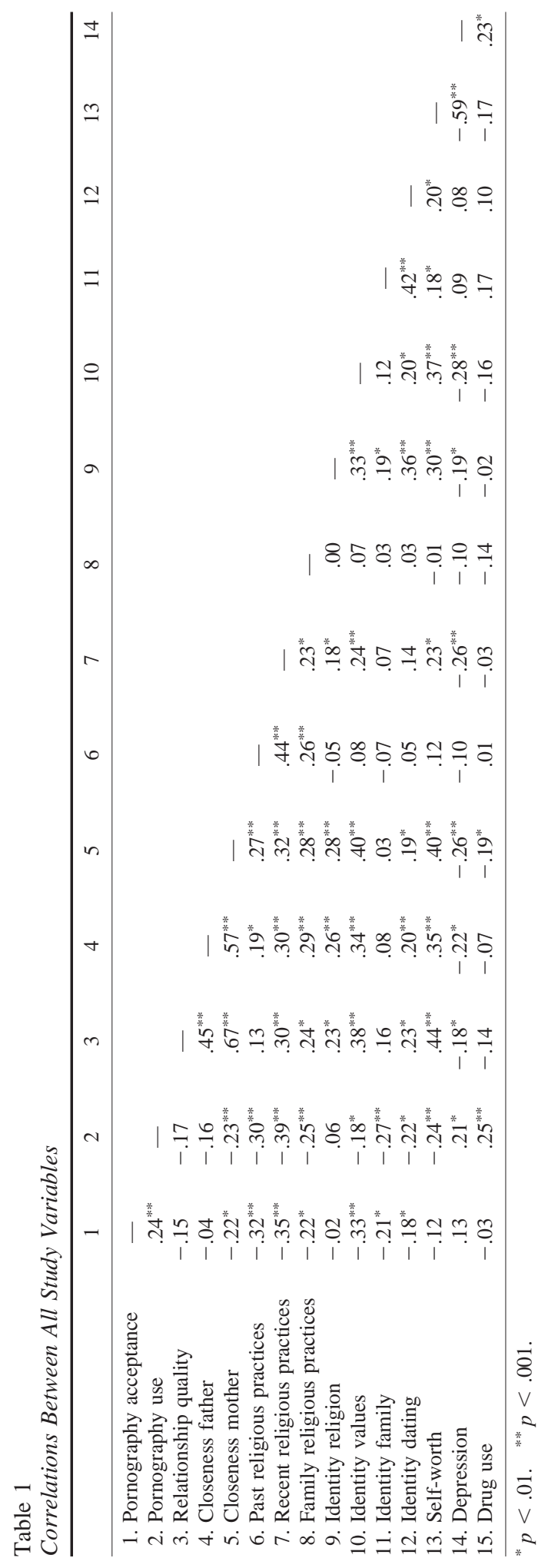


the groups (users of pornography and nonusers of pornography) were not only similar on levels of acceptance of pornography but also on strength of religious beliefs, a univariate analysis of variance (ANOVA) was conducted to determine whether pornography use varied as a function of religious beliefs. Results revealed that there was no difference between the two groups, $F(1,186)=3.65$, ns.

\section{Differences in Pornography Use}

Three multivariate analyses of variance (MANOVAs) were conducted to determine whether there were differences in religious young men's family relationships (parent-child relationship quality, closeness to dad, and closeness to mom), religious practices (past religious practices, current religious practices, family religious practices), and personal characteristics (identity, self-esteem, depression, and drug use) as a function of their pornography use (users vs. nonusers).

Family relationships. The multivariate main effect of pornography use on family relationships was not significant, $F(3,169)=2.48$, ns.

Religious practices and beliefs. There was a significant multivariate main effect of pornography use on religious practices, $F(3$, $178)=7.83, p<.001$. Univariate follow-ups (see Table 2) suggested that nonusers
$(M=5.97, S D=1.02)$ reported higher levels of past religious practices than did users $(M=5.34, S D=1.49)$; nonusers $(M=6.55$, $S D=.67)$ reported higher levels of recent religious practices than did users $(M=6.00$, $S D=1.05)$; and nonusers $(M=5.51$, $S D=1.58)$ reported higher levels of past family religious practices than did users $(M=4.91$, $S D=1.73$ ).

Personal characteristics. There was a significant multivariate main effect of pornography use on personal characteristics, $F(8$, $170)=2.55, p<.01$. Univariate follow-ups (see Table 2) suggested that nonusers $(M=4.76, S D=.73)$ reported higher levels of identity development regarding family than did users $(M=4.41, S D=.82)$; nonusers $(M=4.43, S D=.83)$ reported higher levels of identity development regarding dating than did users $(M=4.18, S D=.88)$; nonusers $(M=3.44, S D=.53)$ reported higher levels of self-worth than did users $(M=3.20, S D=.60)$; and nonusers $(M=2.13, S D=.64)$ reported lower levels of depression than did users $(M=2.39, S D=.75)$.

\section{Discussion}

The purpose of this study of religious young men (all whom considered pornography use to be unacceptable) was to compare those who

Table 2

Differences in Family Relationships, Religious Practices, and Personal Characteristics as a Function of Pornography Use

\begin{tabular}{|c|c|c|c|}
\hline Variable & Non-Users $M(S D)$ & Users $M(S D)$ & $F$-test \\
\hline \multicolumn{4}{|l|}{ Family relationships } \\
\hline Parent-child relationship quality & $3.89(.61)$ & $3.65(.64)$ & $6.29^{* *}$ \\
\hline Closeness to father & $4.14(.82)$ & $4.07(.85)$ & .58 \\
\hline Closeness to mother & $4.46(.58)$ & $4.28(.73)$ & $5.32^{*}$ \\
\hline \multicolumn{4}{|l|}{ Religious practices } \\
\hline Past religious practices & $5.97(1.02)$ & $5.34(1.49)$ & $11.50^{* * * *}$ \\
\hline Recent religious practices & $6.55(.67)$ & $6.00(1.05)$ & $18.65^{* * * *}$ \\
\hline Past family religious practices & $5.51(1.58)$ & $4.91(1.73)$ & $5.80^{*}$ \\
\hline \multicolumn{4}{|l|}{ Personal characteristics } \\
\hline Identity religion & $3.12(.66)$ & $3.25(.66)$ & .98 \\
\hline Identity values & $4.51(.82)$ & $4.31(.89)$ & 2.11 \\
\hline Identity family & $4.76(.73)$ & $4.41(.82)$ & $8.75^{* *}$ \\
\hline Identity dating & $4.43(.83)$ & $4.18(.88)$ & $4.14^{*}$ \\
\hline Self-worth & $3.44(.53)$ & $3.20(.60)$ & $10.32^{* *}$ \\
\hline Depression & $2.13(.64)$ & $2.39(.75)$ & $7.48^{* *}$ \\
\hline Drug use & $.00(.02)$ & $.08(.12)$ & 2.97 \\
\hline
\end{tabular}

${ }^{*} p<.05 . \quad{ }^{* *} p<.01 . \quad{ }^{* * *} p<.001$. 
view pornography with those who do not on indices of (a) family relationships, (b) religiosity (i.e., past/present personal religious practices, and past family religious practices), and (c) personal characteristics (identity development, depression, self-esteem, and drug use). Results revealed that those young men who did not use pornography (compared to those who did) reported (a) higher levels of past and recent individual religious practices, (b) higher levels of past family religious practices, (c) higher levels of self-worth and identity development regarding dating and family, and (d) lower levels of depression. Results for all of the hypotheses will be discussed in turn.

First, it was hypothesized that young men who viewed pornography would have lower quality relationships with their parents. Although bivariate correlations revealed a significant negative correlation between pornography use and acceptance and closeness to mother, multivariate analyses indicated only a possible trend in this regard, which is likely due to there being no bivariate relation between pornography use and relationship quality with fathers. Although significant univariate analyses revealed that pornography users reported lower parent-child relationship quality, and lower levels of maternal closeness than did nonusers, these findings need to be considered with caution given that the omnibus test was not significant, and therefore the findings from the follow-up univariate analyses can, at best, only suggest possible trends for future study.

Indeed, it may be important for researchers to further examine the complex interaction of children's pornography use and relationships with parents who deem its use wrong (post hoc analyses revealed that nearly $100 \%$ of mothers disagreed with the statement that "pornography is an acceptable way to express one's sexuality"), as well as the differential role of mothers and fathers in the socialization of pornography use and acceptance. It is possible that some young people may choose to rebel against their mothers by engaging in a behavior of which they know their mothers disapprove, or may seek pornography use as an outlet to fill the gap left by poor relationships. On the other hand, pornography use may be the cause of the problem in the relationship. Young men may know their behavior would hurt their mothers and they, therefore, pull away in relationships with them.
Another possibility is that mothers may find out about their sons' behaviors and the resulting discussions/arguments might lead to a decline in the closeness and quality of their relationship. Trends from the current study can do no better than point to the parent-child relationship as a possible area for future work, but it would conceptually stand to reason that discrepancies in parental beliefs about pornography use and their son's actual use of pornography could either be a result of or lead to problematic family relationships and therefore is deserving of attention in future research.

Next, it was hypothesized that religious men who viewed pornography, but thought it unacceptable to do so, would have lower ratings of family and personal religious practices while growing up, and lower ratings of current religious practices. Results revealed that compared to individuals who did not view pornography, those who used pornography reported lower levels of (a) past religious practices, (b) recent religious practices, and (c) past family religious practices. As noted previously, past studies have found a negative association between religiosity and pornography use for emerging adults (Carroll et al., 2008; Goodson et al., 2000), but the current study is the first to attempt to examine specific aspects of religiosity including beliefs and practices. There is extant evidence that practices do affect pornography use in that Stack and colleagues (2004) found that church attendance was associated with a $26 \%$ decrease in the odds of cyberporn use. However, their study focused on all adults over the age of 18. By focusing exclusively on 18-27 year olds, results of the current study provide further evidence that religious practices-both past and present, as well as personal and family-are linked to lower levels of pornography use in emerging adulthood. The findings also add lower levels of pornography use to the growing list of positive outcomes associated with religiosity in emerging adulthood, such as healthy attitudes and behaviors, and high self esteem (Knox, Langehough, \& Walters et al., 1998; Rew \& Wong, 2006; Zullig, Ward, \& Horn, 2006), academic and personal-emotional adjustment (Gilliam et al., in press), and lower levels of risk behaviors (e.g., antisocial behaviors, Knox et al., 1998; binge drinking, cocaine use; Hamil-Luker et al., 2004; White et al., 2006). 
It needs to be reiterated that the direction of effects cannot be determined in this study. As noted previously, it may be that young people who view pornography feel embarrassed or guilty (e.g., Goodson et al., 2000) about their behavior and, therefore, do not participate in religious activities such as attending church or saying prayers. However, the retrospective reports of religious practices employed in the study may suggest that by engaging in fewer religious practices as a child, a religious individual may be at greater risk of using pornography in subsequent years. In other words, even if an individual is taught that pornography is unacceptable, religious beliefs may not be enough to prevent pornography use without the regular, maybe even daily, participation in activities (praying, reading scriptures) that reinforce those religious beliefs, including those personally held ethics that pornography is an unacceptable way to express one's sexuality. This possibility is supported by the finding that there were no differences between the groups in regard to personal religious beliefs. While somewhat surprising, the finding underscores the fact that these groups of individuals (pornography users and nonusers) were similarly strong in their religious beliefs; which lessens the possibility that differences in religious beliefs were accounting for the differences between groups rather than pornography use.

Finally, results revealed that young men who used pornography reported lower levels of identity development (in the areas of family and dating) and levels of self-worth, as well as higher levels of depression. There has been speculation (see Fisher \& Barak, 2000; Putnam, 2005) that pornography use may be related to personal characteristics such as depression and substance abuse, but there is markedly little evidence of this in nonclinical and noncriminal populations. While there were no differences in drug use as a function of pornography use, there were significant differences in identity development, depression, and self-worth as a function of pornography use. While Carroll and colleagues (2008) found a link between men's pornography use and numerous externalizing behaviors such as sexual permissiveness, number of sexual partners, and substance use, they did not examine the outcomes specifically for individuals who engaged in pornography while not being accepting of such behavior. For these individuals, the discrepancy between their personal beliefs and actual behavior may cause interpersonal struggles (i.e., cognitive dissonance, e.g., Stone, 2008) that lead to greater problems of an internalizing nature. In other words, this inner conflict between their beliefs and behaviors may account for feelings of depression and lower self-worth.

The findings regarding identity development are also troubling given the importance of identity development during emerging adulthood. While identity exploration was once thought to be restricted solely to adolescents (Marcia, 1966), Erikson (1950, 1968) contended that self-exploration (regarding one's identity) often extends beyond adolescence into young adulthood. Indeed, it is now well understood that identity development is a defining feature of emerging adulthood (e.g., Arnett, 2001, 2004), with research showing that emerging adults rank the resolution of identity-related issues as a defining marker of reaching adulthood (e.g., Arnett, 1997; Nelson \& Barry, 2005; Nelson et al., 2007). Thus, results of the current study suggest pornography use could negatively impact identity development. Specifically, it could lead to greater ambiguity in regard to how one feels about one's identity related to family in that a religious person who believes pornography to be inappropriate but who is using pornography may personally sense that his behavior will affect his ability to have healthy family relationships. In particular, emerging-adult women tend to be both more religious (see Barry et al., in press) and less accepting of pornography use (Carroll et al., 2008) and therefore religious young men may be unsettled about how their behavior will affect their dating and formation of a family and thereby remain unsettled in their identity in that domain.

Taken together, the findings for pornography users may be particularly problematic given the period of development-emerging adulthood. First, emerging adulthood is a time for identity exploration and formation (e.g., Arnett, 2000). Religious young men who use pornography may have more problems with identity formation if they are having to struggle to find a place for pornography use in their identity, especially as it relates to family formation and dating, as well as the perception of oneself as a religious individual who thinks pornography is wrong. Second, emerging adulthood is already a time of 
uncertainly that has been linked to higher levels of depression (e.g., Nelson \& Barry, 2005). If there is an inner struggle brought about by participating in a behavior that is against one's own personal ethic, it may lead to even greater levels of depression as well as lower levels of self worth, which might add to the challenges of this time period. Although it is possible that religious individuals with lower levels of selfworth and higher levels of depression seek pornography as an outlet for these feelings or to avoid social interaction, future research is certainly warranted examining the direction of effects in this regard.

Next, findings are relevant to this period of time given the importance placed on exploration of relationships (e.g., Arnett, 2001, 2004; Barry, Madsen, Nelson, Carroll, \& Badger, 2009). Pornography is usually viewed as an individualistic behavior. Seldom is it studied in the context of relationships. It is possible that both beliefs, behaviors, and outcomes related to pornography and its use differ, and may even be more pronounced, depending on whether or not one is in a committed relationship. This is especially salient given that women are much less accepting of pornography use than are men (Carroll et al., 2008), and suggests there is certainly a need to examine pornography's impact in the context of romantic relationships. Finally, in another relational context, emerging adulthood is a period during which young people are simultaneously seeking greater autonomy from their parents (see Arnett, 2004) and striving to develop a more mature and equal relationship with parents (e.g., Arnett, 1997, 2003). Pornography may be a roadblock in this process if it negatively impacts parent-child relationships, as bivariate correlations and trends from our study hint may be happening, particularly with mothers.

In sum, it appears that pornography might present a problem in an emerging adult's life if its use is at odds with his internal ethic (i.e., that pornography use is not an acceptable behavior), suggesting that congruence between one's personal beliefs and personal behaviors is important for one's development in emerging adulthood. Furthermore, it appears that practices that reinforce beliefs might help keep behavior and beliefs in alignment. Specifically, findings reveal that engaging in regular religious practices might contribute to lower levels of pornography use. While future work is needed to determine causality, it may be that religious practices help a young man refrain from behaviors that are inconsistent with his personally ascribed ethics, over and above what beliefs alone are able to do.

\section{Limitations and Future Directions}

This study is not without limitations. First, as noted throughout the manuscript, the correlational nature of the data precludes causal inferences. However, despite their own limitations, the retrospective view regarding past religious practices may be some of the first evidence suggesting that early behavior may be linked to pornography use in emerging adulthood. Future work should examine these relationships using a longitudinal design. Second, the sample consisted of only religious college students, who may not be representative of the larger population. Work is needed with a nonreligious college group and also non-college-attending emerging adults, to determine additional factors, other than religiosity, that might lead to cognitive dissonance regarding pornography use. While Cooper, Delmonico and Burg (2000) identified college students as a group that is at-risk for cybersex compulsion, it is not clear whether this is due to their age or to their status as students. Future work with nonreligious students as well as noncollege participants is needed in order to be confident in the generalizability of these findings. Next, the sample was drawn from only one religious institution affiliated with only one religion. Future work is needed that draws on a greater range of religious affiliations to assess whether this is religion specific or applies to most religious individuals who are not accepting of pornography use. Finally, there are limitations with the way in which both acceptance and use of pornography was measured. Both constructs were measured by a single item, which needs to be expanded in future work to better assess the complexity of beliefs about pornography. Similarly, the pornography use group was formed by grouping anybody who had used pornography to any extent in the last month. It may be that the findings are more pronounced for those who use it most frequently.

Despite these limitations, the current study provides one of the first attempts to better un- 
derstand the correlates of pornography use, and suggests that although correlates appear to be negative even when controlling for religiosity in a normative sample (Carroll et al., 2008), that negative correlates may be even more pronounced among individuals who do not believe pornography use to be an acceptable way to express one's sexuality. Specifically, results suggest that discrepancies between beliefs and behaviors related to pornography were associated with religious practices, identity formation, self worth, and depression. Given the prevalence of pornography use by young men in today's society (e.g., Carroll et al., 2008), these findings contribute to the growing understanding of how it may be linked to a young person's development during emerging adulthood.

\section{References}

Arnett, J. J. (1997). Young people's conceptions of the transition to adulthood. Youth \& Society, 29, 3-23.

Arnett, J. J. (2000). Emerging adulthood. American Psychologist, 55, 469-480.

Arnett, J. J. (2001). Conceptions of the transition to adulthood: Perspectives from adolescence to midlife. Journal of Adult Development, 8, 133143.

Arnett, J. J. (2003). Conceptions of the transition to adulthood among emerging adults in American ethnic groups. In J. J. Arnett \& N. L. Galambos (Eds.), New directions for child and adolescent development: Exploring cultural conceptions of the transition to adulthood, 100 (pp. 63-75). San Francisco: Jossey-Bass.

Arnett, J. J. (2004). Emerging adulthood: The winding road from the late teens through the twenties. New York: Oxford University Press.

Balistreri, E., Busch-Rossnagel, N. A., \& Geisinger, K. F. (1995). Development and preliminary validation of the Ego Identity Process Questionnaire. Journal of Adolescence, 18, 179-192.

Barry, C. M., Madsen, S. D., Nelson, L. J., Carroll, J. S., \& Badger, S. (2009). Friendship and romantic relationship qualities in emerging adulthood: Differential associations with identity development and achieved adulthood criteria. Journal of Adult Development, 16, 209-222.

Barry, C. M., Nelson, L. J., Davarya, S., \& Urry, S. (in press). Religiosity and spirituality during the transition to adulthood, International Journal of Behavioral Development.

Boies, S. C. (2002). University students' uses of and recreations to online sexual information and entertainment: Links to online and offline sexual behav- ior. The Canadian Journal of Human Sexuality, 11, 77-89.

Buchanan, C. M., Maccoby, E. E., \& Dornbusch, S. M. (1991). Caught between parents: Adolescents' experience in divorced homes. Child Development, 62, 1008-1029.

Carbery, J., \& Buhrmester, D. (1998). Friendship and need fulfillment during three phases of young adulthood. Journal of Social and Personal Relationships, 15, 393-409.

Carroll, J. S., Padilla-Walker, L. M., Nelson, L. J., Olson, C. D., Barry, C. M., \& Madsen, S. (2008). Generation XXX: Pornography acceptance and use among emerging adults. Journal of Adolescent Research, 23, 6-30.

Cooper, A., Delmonico, D. L., \& Burg, R. (2000). Cybersex users, abusers, and compulsives: New findings and implications. Sexual Addiction and Compulsivity, 7, 5-29.

Erikson, E. (1950). Childhood and society. New York: Norton.

Erikson, E. H. (1968). Identity: Youth and crisis. New York: Norton.

Fisher, W., \& Barak, A. (2000). Online sex shops: Phenomenological, and ideological perspectives on internet sexuality. Cyber Psychology and Behavior, 3, 575-589.

Gilliam, A. K., Barry, C. M., \& Bacchus, N. A. (in press). The relation between stress and college adjustment: The moderating role of spirituality. Modern Psychological Studies.

Goodson, P., McCormick, D., \& Evans, A. (2000). Sex on the Internet: College students' emotional arousal when viewing sexually explicit materials on-line. Journal of Sex Education and Therapy, 25, 252-260.

Gunnoe, M. L., \& Moore, K. A. (2002). Predictors of religiosity among youth aged 17-22: A longitudinal study of the National Survey of Children. Journal for the Scientific Study of Religion, 41, 613622.

Hamil-Luker, J., Land, K. C., \& Blau, J. (2004). Diverse trajectories of cocaine use through early adulthood among rebellious and socially conforming youth. Social Science Research, 33, 300-321.

Hinckley, G. B. (2000, June). Recurring themes of President Hinckley. Ensign, 30, 18.

Knox, D., Langehough, S. O., \& Walters, C. (1998). Religiosity and spirituality among college students. College Student Journal, 32, 430-432.

Lewis, C. A., Shevlin, M., McGuckin, C., \& Navrtil, M. (2001). The Santa Clara strength of religious faith questionnaire: Confirmatory factor analysis. Pastoral Psychology, 49, 379-384.

Marcia, J. E. (1966). Development and validation of ego identity status. Journal of Personality and Social Psychology, 5, 551-558. 
Neeman, J., \& Harter, S. (1986). Manual for the selfperception profile for college students. Unpublished manuscript. Denver, CO: University of Denver.

Nelson, L. J., \& Barry, C. M. (2005). Distinguishing features of emerging adulthood: The role of selfclassification as an adult. Journal of Adolescent Research, 20, 242-262.

Nelson, L. J., Padilla-Walker, L. M., Carroll, J. S., Madsen, S., Barry, C. M., \& Badger, S. (2007). 'If you want me to treat you like an adult, start acting like one!' Comparing the criteria that emerging adults and their parents have for adulthood. Journal of Family Psychology, 21, 665-674.

Putnam, D. E. (2000). Initiation and maintenance of online sexual compulsivity: Implications fr assessment and treatment. Cyber Psychology and Behavior, 3, 553-564.

Regnerus, M. D. (2007). Forbidden fruit. New York: Oxford University Press.

Rew, L., \& Wong, Y. J. (2006). A systematic review of associations among religiosity/spirituality and adolescent health attitudes and behaviors. Journal of Adolescent Health, 38, 433-442.

Rothbart, M. K., Ahadi, S. A., \& Evans, D. E. (2000). Temperament and personality: Origins and outcomes. Journal of Personality and Social Psychology, 78, 122-135.
Sherkat, D. E., \& Ellison, C. G. (1997). The cognitive structure of a moral crusade: Conservative Protestantism and opposition to pornography. Social Forces, 75, 957-980.

Stack, S., Wasserman, I., \& Kern, R. (2004). Adult social bonds and use of internet pornography. Social Science Quarterly, 85, 75-88.

Stone, J. (2008). To practice what we preach: The use of hypocrisy and cognitive dissonance to motivate behavior change. Social and Personality Psychology Compass, 2, 1024-1051.

White, H. R., McMorris, B. J., Catalano, R. F., Fleming, C. B., Haggerty, K. P., \& Abbott, R. D. (2006). Increases in alcohol and marijuana use during the transition out of high school into emerging adulthood: The effects of leaving home, going to college, and high school protective factors. Journal of Studies on Alcohol, 67, 810-822.

Zullig, K. J., Ward, R. M., \& Horn, T. (2006). The association between perceived spirituality, religiosity, and life satisfaction: The mediating role of self-rated health. Social Indicators Research, 79, 255-274.

Received September 10, 2009 Revision received January 20, 2010 Accepted January 21, 2010

\section{E-Mail Notification of Your Latest Issue Online!}

Would you like to know when the next issue of your favorite APA journal will be available online? This service is now available to you. Sign up at http://notify.apa.org/ and you will be notified by e-mail when issues of interest to you become available! 